keeps the eyelids closed till the aqueous humour no longer escapes from the corneal wound; that is, till the cornea is quite healed. At the end of the week, when the patient has opened the eye, Mr. Walton does not raise the lid limself, but desires the patient to open the eye naturally, which he con. siders far preferable; he again closes it, if requisite, with court plaster for some days. There can be no doubt of the prudence of this. Many an instance of prolapse of the iris, with all the irritation and ulterior consequences, has been produced by the use of the eve before there has been proper reunion. Young operators are often sadly puzzled to account for the secondary imperfection of prolapse of the iris, after they have had such promising results when the eye was looked at a few days after the operation. 'This is the solution : the eye is used far too soon, and by the action of its own muscles, the prolapse is occasioned.

The great proof of cicatrisation of the cornea is the fulness of the anterior chamber. So long as the iris is pressed forwards, and there is not the natural accumulation of aqueous fluid, the eye should be kept closed. A very little attention will enable the practitioner to decile this point.

When the iris is wounded in the operation of extraction, prolapse is very ant to occur under any condition : hence, Mr. Walton lays it down as a rule, that much pains should be taken to prevent the accident. He considers it far better on every occasion to finish the operation with the secondary knife rather than to complete it with the cataract knife, when by so doing the iris is at all injured. The late Mr. Alexander, than whom there never was a better operator, always made the section of the cornea with two knives. As soon as he had effected the counter-puncture with Wenzel's knife, he withdrew it, and completed the section with the secondary knife.

\section{Briginal Commumications.}

\section{SOME OF THE PRINCIPAL EVENTS IN 'THE CLINICAL HISTORY OF ASTHMA.}

By IIYDE SALTER, M.D., F.R.S., Fellow of the Royal College of Physicians, and Assistant-Physician to Charing Cross Hospital.

Havisg elsewhere (Medico-Chirurgical Review, July 1859) described the phenomena of the asthmatic paroxysm, I purpose in the present paper to direct attention to those general features of asthma that characterise it as a whole-those different events that develope themselves in the course of the disease, and whose variations and combinations impart the distinctive features and individuality to each case. Such general features of the disease arise from the relations of the paroxysms to each other, their relations to the subject of them in respect to age, sex, etc., the modifications they undergo, and certain of the effects they produce, and may be called, in opposition to the phenomena of the paroxysm, the phenomena of the intervals, or, perhaps more correctly, the phenomena of the discase.

Of these events in the clinical history of asthma, the prin. cipal are the following:-

1. Periodicity ; 2. Habitude; 3 . Change of Type; 4. Tendeney ; 5 . Capricionsness; 6. Physiognomy; 7 . Time of life of first access; 8. Influence of Sex; 9. Hereditariness.

\section{I.-Peniodicity.}

Asthma is one of the few diseases that can be strictly pronounced periodic. It is not merely paroxysmal, it is periodic : the paroxysms occur at regular and definite periods. And this periodicity may be said to be typically characteristic of the disease; it is the most pronounced in those cases that are in other respects the most uncomplicated and best marked specimens of it. But although the absence of periodicity in a given case deprives the disease of one of its best marked features, it is by no means constant; in some cases it is but slightly marked-the periods vary a good deal; and in some it is entirely lost. In others, however, the regularity is most curious; as the period characteristic of the particular case recurs, the attack is predicted with the greatest certainty, and never fails to appear at the right time-never misses, never anticipates, never postpones. In the length of the intervals, although in each case it is constant and characteristic, there is the greatest variety-from a day to a year. Nany of these intervals appear to be arbitrary, and one cannot make out at all why they should be, as it were, chosen: many of them, however, are natural-the measures of certain cycles, the period of recurrence of certain conditions, either in the external world or within the body, so that their agency in determining the frequency of the paroxysms is easily inteiligible, inasmuch as they measure the interval from one occurrence of the exciting cause, or the condition of susceptibility, to another. Such periods are a day, a week, a month, a year; and these are all of them very common measures of the asthmatic interval. For example, diurnal asthma is very common. A patient comes to you and tells you, that every morning precisely at the same hour, say four o'clock, a dry wheezing difficulty of breathing wakes him, and obliges him to sit up in bed, or leave his bed altogether, and go through, in short, all the suflerings of a regular asthmatic attack. Such a case came under my observation only yesterday. A poor woman, aged 5: (Miary Baker, Case -), who had never had asthma before, came to me at the hospital, and told me that for the last five months she has been awoke every morning between four and five o'clock with severe dry wheezing dyspnœea, obliging her to sit up for about an hour, or get out of bed, labouring for her breath with great distress. In about an hour, the urgency of the dyspnuea abates, the wheezing gets moister, a slight expectoration comes to her relief, and she is able to lie back and get a little imperfect sleep : it is not, however, till she has been up about an hour-that is, about eight o'clock-that the difficulty of breathing entirely leaves her. When I saw her, in the middle of the day, she was breathing as well as I was; and so she continues all day. She goes to bed quite well, lies down as well as ever, and sleeps undisturbed till four or five the next morning, when she is awoke as before.

Now this diurnal period is very common where asthma is associated with chronic bronchitis, heart disease, etc. Indeed, it is the period of impure asthma, of asthma grafted on organic disease of the heart or lungs; and wherever I meet this invariable morning recurrence, $I$ always suspect it is not simple asthma, and look out for some permanent heart or lung mischief. And one can easily understand why this should bo so. The condition of sleep, and the recumbent posture, bring a diurnal aggravation of the permanently existing conditions, giving rise to the bronchial spasm; and the time of the nigh at which the asthma comes on, and the patient is awaked, depends upon the length of time required for this diurnal aggravation to produce such an amount of asthmatic contraction of the bronchial tubes, as to render the continuance of sleep impossible. If the organic cause of the asthma exists to any considerable extent, the patient will be sure to have the asthma every night; for the organic condition is constant, and it will be impossible for the patient to assume the horizontal position and the condition of sleep long without this aggravation of conditions giving rise to asthna. The impeded circulation through the lungs, in heart disease, or the inflamed and irritable state of the bronchial muccus membrane, in chronic bronchitis, is not adequate, while the patient is awake and erect, to the production of bronchial spasm; but sleep and recumbency soon render them so, partly by aggravating them, partly by ex alting reflex susceptibility in the way I have more fully explained elsewhere. (IIedico-Chirurgical Review, July 1\$58).

Once in the twenty-four hours he lies down and sleeps, and, therefore, once in the twenty-four hours he has an attack of asthma. But were it not for the organic disease, (say heartdisease) the mere sleep and horizontal position would not produce that embarrassment and arrears of the respiratory function which induce the asthmatic spasm.

I would say then, wherever the asthmatic period is diurnal, look out for organic disease. But this does not always hold good. The nightly recurrence of asthma does not necessarily imply that it has an organic basis. In the woman I was mentioning just now there was not a trace of organic disease. The respiratory sounds were perfectly natural; there was no prolongation of expiration, the breathing was very deliberate, with plenty of surplus time; the post-expiratory rest was long; the heart was quite normal. I have seen auother such case this very morning (case of Mary Anne Frost, Case - ).

Where the asthma is dependent upon the state of the digestion, the diurnal period is very common. The patient will have an attack every afternoon after dinner, lasting for two or 559 
three hours, till digestion is over. This is so very common that I shall not cite cases of $j$. As a rule we may say that, where the period is diumal, the attack depends on some dailyrecurring exciting cause. But even this is not universally true, for I have known cases where the attack recurred daily under such varying circumstances, and at times so free from any dis. coverable exciting cause, that the reason of its daily rhythm appeared to be unaccountable. In these cases we must seek another explanation of the diurnal period, to which I shall refer presently.

Once a week is a very common interval, at the same hour of the same day, as the week comes round, and at no other time. I remember one very remarkable instance of this in an asthmatic boy, who for years had an attack every Monday morning. On every other morning in the week he awoke well; but as surely as Mionday morning returned, so surely did his asthma appear. A suspicion arose on the part of his parents that he was malingering. His lessons on Monday morning were different from those on other days, and they thought he might be shamming, or at any rate making the most of lis complaint in order to escape school. It was not till this had been going on for a long time that the real cause became evident:-on Sunday evening he took supper, on other evenings not, and the Monday morning's asthma was caused by the Sunday evening's supper. On tiking supper on other occasions it was found that asthma invariably followed, and this cleared up the Monday morning's mystery. He left the suppers off', and the regular Monday morning's asthma vanished. It is probable that in most asth. mas with the weekly period, the interval is due to the recurrence of the same exciting cause in some part of that seven day's circle in which life, in all Christian countries, moves.

'The fortnightly interval, which is by no means a rare one, is probably due to the same cause; the weekly rhythm determining the period, but the interval proper to the case being longer than once a week. I have such a case under my care at the present tilite, in a young asthmatic who for some years rast has had in attack regularly once a fortnight, and, as in the preceding case, it is always on the Monday morning. He cannot, however, attribute it to eating supper on Sunday night, for he never does so; but he can and does assign it to something peculiarly characterising Sunday, and believes that it is caused by the unusual amount of exercise that he takes on that day.

The munthly interval, as far as I have observed, is due to the menstrual period. I have never seen or heard of any case of it, well ani regularly marked, except in women, and in cases of what appeared to be clearly hysterical asthma. But of hys. terical asthma, it is, as might be expected, the characteristic interval; and $\mathbf{I}$ should always, in a monthly asthma in a woman, look out for a uterine cause.

Asthma occurring once a year is almost always winter asthma, and alnost always a complication of astima with bronchitismuscular spasm engraftel on inflammation of the mucous membrane of the air passages. These cases, as I shall show elsewhere, are not really cases of asthma at all ; that is, not primary and idiopathic asthma. Asthma they must be; wherever there is paroxysinal constriction of the air passages, there is asthma; but the asthma is not the substantive disease, it is a mere appendage to the bronchitis. Such cases are always well from spring to autumn, and their winter asthma is not one at tack, but an irregular succession of attacks, varying as the bronchitis. There is, however, one kind of annual asthma that is not a winter asthma, but a surnmer asthma; and that is, that curious disease called hay-fever or hay.asthma. 'This begins and ends with the hay season, and varies in the time of year according as the hay season is early or late. As long as the grass is in flower it persists, with that it ceases. Its visits are therefore restricted to about a month or six weeks in the early summer. It is not constant throughout this time as one attack, but comes and goes with those other symptoms of irritation of the respiratory mucous membrane, of which it is a part. The neighbourhood of hay, bright, hot, dusty sunshine, a full meal, laughter, etc., suffice, at any time during the hay season, to bring it on. It often afrects a sort of diurnal rhythm, being generally worse at night. While this condition lasts, the astlima is often so severe as to deprive the sufferer of sleep for nights together, and he leaves his bed in the morning palid, blear-eyed, and worn out. When the hay season is over every symptom vanishes, and for ten or eleven months the patient may calculate on a perfect immunity from even the slightest asthmatic sensation.

I find there is a third form of annually-recurring asthma besides these two, the winter and the hay asthma, it is asthma whose severe attacls are confined to the hot weather of the 560 late summer and early autumn. It is not at all uncommon for asthma to be so much worse at this time of the vear--about August, and a little before or after-that it may be almost said to be confined to this period; the manifestations of the asthmatic tendency at other times of the year being so slight as hardly to attract any attention. I possess the nutes of several cases in which this autumnal recurrence of the disease was well marked. Why asthma should be worse in hot weather I think would be difficult to explain; of the fact there is no question. Even in cases that exist all the year round it will frequently be found to be worse in sultry July weather than at any other time, and more especially if the weather is thundery as well as hot. I have the notes of as many, I should think, as six cases in which the connection between thunder and asthma was well marked.

The intervals, however, which many cases of regular periodic asthma choose, are, though constant, quite arbitrary, as, for in stance, ten days, a fortnight, three months.

There is one curious circumstance about asthma that clearly shows that its periodicity is inherent--part of the disease. It is, that each attack seems to impart, for a time, an immunity from a repetition of it. For some time after an attack, the time varying according to the interval characteristic of that particular case, the patient may expose himself to the ordinary exciting causes of the paroxysms without the slightest fear of inducing one. As this period draws to a close, exposure to the provocatives of the attacks is attended with more and more risk; and when it has transpired the slightest imprudence is certain to bring on a fit. Incleed, so great does the asthmatic tendency after a while become, that no amount of care will succeed in warding it off:

For example, suppose that the exciting cause of the attacks is tood, unwholesome in character, or taken late in the day, and suppose that the interval is monthly. For a week or two after the attack, the patient may take supper with impunity; towards the end of the month he does so at great risk; when the month is up he does so with the certainty of bringing on his disease; but he may keep it at hay for some days by extraordinary care in his diet. Beyond that time, however, the most scrupulous care will not avail to postpone the paroxysm. This curious feature, in which asthma so much resembles epilepsy, suggests to one's mind the idea that each attack is a sort of clearing shower: that in the intervals between the attacks an unknown something-that particular condition of nervous system in which the peculiarity of the asthmatic consists-accumulates, and that each paroxysm is the discharge of this accumulated condition. At any rate, this is the sort of idea that the phenomena suggests to one's mind, and I am not sure, a mere analogy as it appears, that it does not come nearer to the true expression of the pathology of the truly periodic non-organic cases than any other illustration or explanation that could be offered.

But we must not run away with the idea that an exact periodicity is by any means a coustant feature of asthma. In the majority of cases, if you ask asthmatics how often their attacks occur, they will mention some definite period, although their specification may not be precise, or may be accompanied with the qualification that it varies a little-about every ten days o a fortnight, or about every two months. In those cases in which the occurrence of an attack depends upon the occurrence of some unknown exciting cause, the degree of regularity will, of course, depend upon the regularity of the recurrence of that cause, which is often a mere approximative regularity and it so happens that many of the provocatives of asthrna are quite arbitrary in the period of their recurrence; as, for instance, a debauch, a late dinner, a fog, and may, some of them, be varied at will. In these cases, of course all exact periodicity would be lost; the cause being irregular, so will be the attacks; and in those cases where the cause is entirely under the control of the individual, as, for instance, where it depends on the lind of food or time of taking it, the attack may be brought on at any time and as often as the asthmatic wills; or, by rigid abstention from the exciting cause, the period may be indefiuitely prolonged. have known, for example, the same asthmatic bring on an at tack twice a week because he dined late and unwholesomely twice in that time, and keep off an attack for many months by simply abstaining from this one exciting cause. Of course, i he had dined late and largely once a week, or once a month, his asthma would have been periodic, with those respective intervals.

There are, however, a large number of cases of pure, uncom plicated, spasmodic asthma, in which, without any recognised 
exciting cause of irregular recurrence, all trace of neriodicity is lost. The patient does not know when to expect his attack. He may have one in a twelvemonth, he may lave one to-morrow, he may have four in a month, he may go rears without one; it may never occur at two intervals alike, and when it does occur he is perfectly at a loss to say why it should choose that particular period. The time of its recurrence and its frequency are alike inexplicaule. He may be living in periect heal hand daily dread.

To express summarily, then, what appear to be the fucts with regard to the periodicity of asthma, we may say-

1. That asthma is typically periodic.

2 . 'That, though there is a period for each case, there is no particular period for the discase in general.

3. 'That the periolicity of asthma is of two kinds, intrinsic and extrinsic, the latter a spurious periodicity, dependent on the periodic recurence of the exciting cause; the former, the true essential periodicity, independent of ail external circumstances.

4. That periodicity, though a common, is not a universal feature of asthma.

\section{I P H T II E R I .}

By Ronnit S. Cross, Esq., Petersfield.

I BEG to submit the annexed remarks, with the illea of fulfilling one great purpose of car Association-the recording of individual observation, with a view to building up experience deduced from facts.

Throughout these last eighteen months, this town and neighbourhood have been visited by throat-disease in various forms; considerably above a humdred cases, of a diphtheritic character, having occurred under my observation, varying in character fiom the mild form, in which small spots of white easily detached Jympin or exudation memlirane, on more or less enlarger and inflamed tonsils, was the type; little or no constitutional disturbance being present; to the most severe kind, suddenly ushered in by severe symptoms of exhaustive febrile action; the tonsils, urula, and whole of the parts at the back of the mouth as low down as could be seen, were coated with a diry white, or brown grey, firmly adhering membrane; life being destroved in a few days, sometimes by extension to parts necessary fir respiration, but as often ly apparently a state of exhanstion of the system being induced, in which death occured sometimes very unexpertedly.

Two cases (in one family, of six children, the oldest eleven years, and all of whom, with the exception of the infant, had the disease) were sufficiently remarkable to descrve a separate notice. In two boys, aged respectively ejolit and nine, the throat symptoms were very severe from the first. About the fifth day, healing set in: so rapidly, that, by the end of the seventh, a sloughing ulcer, which had embraced the whole of the parts at the back of the mouth within the reach of observation, were quite well. One day only of apnarently perfect convalescence intervened; and vomiting set in, with pain and tenderness over the epigastrium, extending particularly to the hepatic region. 'There were constipation; total loss of appetite; prostration ; rapid emaciation; thirst ; and, in one case, there was intense pain in the head for the last fortyeight hours. One boy died at the end of three weeks of such condition; the other, at the end of ten dars.

A very careful post mortem examination of the last case was made. The tonsils appeared gone; i.e., their site was occupied by some loose irregular granulations, which had the character of remaining, the inter'stitial structure being absent. There was no extension of the disease into either csophagus, or larynx and truchea. 'The lungs were healthy. The liver was enlarged and pale. 'The stomach contained about half' a pint of greenish viscid fluid. The mucous membrane, particularly at the edges of the rugre, which were very prominent, was of a deep cliocolate, almost mahogany colour; the colour was not distributed in patehes, although there were degrees of depth of shading, varying from this to deep rose colour and red, but pervading the whole, and extending a long way-I should say, throughout the whole of the small intestines, most intersely in the duodenum. The mucous membrane was softened and thickened, and presented at the two orifices an appearance of a separation, as though it might readily be detached.

'The disease in question has occurred in all situations and among all classes. 'The mortality has been about ten per cent. of the whole. This ratio, I should remark, includes as well those cases in which application has heen made too late to offer any reasonable chance of doing good, as it does those in which everything has been done from the very first moment of attack. As to contacioin, I have been unable ciearly to trace this cause in more than one case; as in those fanilies where two, three, or more children were the subjects of the disease, the cases have occurred at such intervals as to preclude the idea of such being the exciting cause; and, moreover, often only one has had it, even where the discovery was made too late for any attempt at isolation. One adult has dicd; and one who had it, hai been nursing a child with angina, she herself having been the sulject of scarlet fever since adolescence. Albumen has been sometimes present in the urine; sometimes not. I should say, that on the average the subjects of the malady had nut been remarkable for their apparent vigour of constitution, but rather the least robust and healthy of the community.

The treatment has consisted of sulphate of zinc or ipecacuanha emetics, with a mild calomel purge, followed by mineral acids, with bark or quinine; sometimes citric acid, chlorate of potass, tincture of sesquichloride of iron, etc.; with applications of nitrate of silver, solid and in solution (five grains to one drachm); solution of chlorinated soda, hydrochloric acil, ete., diligently applied by sponges, and gargles of like character: externally, an embrocation of compound camphor liniment, soap liniment, and landanum. Leeches were applied in one case, followed by a blister, which caused a most un healthy sloughing sore, which undoubtedly accelerated the end. And here I may mention one unfarourable symptom always attendant on the severer forms; i.e., a filling up from ear to ear under the chin, with a hard, tense, brawny kind of shining swelling, coiresponding to a similar infiltration of at the internal parts.

The diet has consisted of beef-tea and nutritions bland nutriment, with wine, according to its apparent necessity. On the first and second lay, if given, wiwe appeared to aggravate the constitutional irritution already severe; and in like man. ner, about the third day, when the exudation membrane was beginning to separate, allowing the escape of a highiy offensive discharge. Caustic or any pungent application io the throat seemed to do harm from the same canse.

\section{I P H T H E R I A.}

By Geonge Botroniex, Esq., Croydon.

Maxy valuable records of cases have appeared almost weekly in the medical periodicals for months past, mostly differing from ench other as to the nature of the epidemic, as well as to the mode of treatment. It would, therefore, be highly desirable that some better defined pathological character of the disease should be regreed unon by the medical profession, and also a general plan of treatment laid down, as in all other diseases.

It appears that, at present, we cannot do more than give our individual opinions, founded ripon practical experience.

In the first place, it may be remarlied that the disease assumes very neurly the same train of symptoms in all places.

From what has been written unon the subject, it appears that some believe it to be a new disease; others, that it is accornpanied with scarlet fever. It therefore becomes our duty, if possible, to find out which view is correct.

In discussing the nature of this disease, its pathological character should be settled; but, having had but one fatal case in my own practice, my experience from post mortem examinations will not do much. I can, therefore, only ofter my opinion from the cases I have had under treatment.

It appears to me that at the commencement of the attack there is but slioht congestion of the mucous membrane of the pharynx, accomponied with slight constitutional disturbance; but, in a few hours, the membrane puts on a livid appearance, and runs rapidly into the gangrenous state: and that the false membrane is a deposit of layers of lymph in the early stage of the disease, which soon loses its vitality, and acts as an extraneous body, thereby preventing the parts from performing their natural functions. Accompanying this change, great depression of the vital powers of the system takes place.

Now whence arises the rapid and fatal change in a few hours? Is it not from metecorological canses? for it is certain that locality lias but little to do with it. It has been as severe in high and dry situations as in low and damp; in isolated 